\title{
Life, Death, and What is between Them? A Sneaky Look at the Other Bank
}

\section{George Makhoul Nader ${ }^{*}$}

Department of Ophthalmology Faculty of Medicine, Damascus University, Salmiya, Hawally, Kuwait

“Corresponding author: Nader GM, Faculty of Medicine, Damascus University, Salmiya, Hawally, Kuwait, Tel: 0096597369045; E-mail: georgenader44@hotmail.com Received date July 30, 2017; Accepted date: August 6, 2017; Published date: August 16, 2017

Copyright: 2017 (c) Nader GM. This is an open-access article distributed under the terms of the Creative Commons Attribution License, which permits unrestricted use, distribution, and reproduction in any medium, provided the original author and source are credited.

\begin{abstract}
When asked about the conclusion they reached, the lesson they learned, or the philosophy they created, based on their experience with death, regarding the existence or non-existence of another life after death, their responses
\end{abstract} varied according to their cultural and religious (or non-religious) backgrounds.

Some of them denied the existence of another life, and considered that the person who dies... dies... but he remains alive in the memory of his beloved ones or in the memory of the generations if he has achieved in his life what makes him immortal. In other words, the other life, in the view of those, is a "thought" rather than a "being."

Others were nihilistic, melancholic, and considered that death is equivalent to total absence or vanishing.

The larger proportion, as expected, considered that other life is a fact and a reality, and that those who leave the earthly life move to live in peace and tranquility with their predecessors.

But again, nobody ever mentioned sensual details in any aspect of the other life as they see it.

\section{Keywords: Resuscitation; Schizophrenia; Paramedics;} Hallucinations; Endorphins; Delusions

\section{Introduction}

This puzzle might be considered as one of the greatest puzzles that occupy most people's minds, regardless of their intellectual and cultural levels, and it does not seem to find its way of solution in the foreseeable future, scientifically speaking [1].

What happens to us after death? Is there another life? What is its form? And what are its components? And many other questions that are parts of the big basic question - puzzle.

This article is not intended to dive in this subject from its religious side. The answers given by religion to this mystery are available to everybody; clear and conclusive answers. And those who find these answers sufficient and enriching, there is no need for them to read this article.

However, even if this latter category has read it, it is harmless; they can read it as an entertainment or time skipping.

This article does not aim, on the other hand, to conflict with religion or arguing it. It is just an invitation to think differently. It is an invitation, not to provide ready answers, but to ask more questions.

Many times, it occurs that the answer lies deep hidden within the question itself.

\section{Definition of Death from a Medical and Legal Point of View}

There is no comprehensive definition of death that is agreed by all physicians so far, but it can be defined in a simplified way: Death means full and permanent cessation of vital functions of the body.

But why is that confusion about the definition of death, while its definition seems so simple? It is because; each of the words in the previous definition needs to be defined in turn. While it seems very simple, linguistically speaking, it is in fact very sophisticated.

Before declaring the state of death, it must be verified that vital functions, namely the heart, the circulation and the respiratory system, have completely stopped, not only slowed down by a significant reduction in body temperature $[2,3]$.

But verification of cessation of the vital functions does not mean that death has occurred. This cessation must be permanent. And this issue is subject of many interpretations and differences regarding the period of time that should pass after the cessation of heartbeat and breathing movements, and the failure of resuscitation efforts to recover them, before the cessation is considered to be permanent.

But hey, that's not all. The above describes only an interim part of the chain of events of the death process. This part is the clinical death only.

This is not death, not yet.

This phase is followed by biological death, a series of events that end with the death of all organs cells, starting from the brain. At the end of this stage, and only at the end, the state of death is declared. 
Theoretically, a clinically dead person has a chance, albeit small, to return to life. Of course, I mean, if this death occurred in a hospital, which is sufficiently equipped. For example, entering the biological death stage can be delayed by significantly reducing the body temperature to make the metabolic needs minimal, while continuing the resuscitation process for some time before being placed on the cardiopulmonary bypass.

But if the clinical death occurs and the resuscitation process is not started immediately, the brain will undergo hypoxia due to interruption of blood flow because of cardiac arrest. If this hypoxia persists for more than a few minutes, the brain cells will die, and this death will soon progress to become universal within a few more minutes, then biological death takes place [4].

Of course, it may happen in a reversed way. The brain cells might die while the vital functions remain intact. This condition is known as the vegetative state, meaning that the affected person turns into something resembling plants or vegetables; he breathes, receives food through a feeding tube, and gets rid of the wastes in the same manner, nothing else he does.

But the definition of death does not apply to this latter condition. It is only a transformation from a form of life to another form; from a human being to a plant or vegetable (I mean it in medical and legal sense, so that no one would consider this expression humiliating to the human soul).

And now back to that space between clinical death and the initiation of biological death events series. This space is the only window that allows us to view the other bank or the other world, as many like to call it, and then return back to the bank of life. This window is specifically targeted by this article.

I was about 15 years old when I accidentally heard a pilot, who barely survived the crash of his aircraft during of the 1973 war, telling his story. That pilot was unable to precisely determine how long he had lost consciousness (or life), but he assured that it was no more than one minute, based on the documented timing difference between the moment of his aircraft crash and the moment of him being requesting help from his team. What's amazing in his story is that his sense of time has gone far beyond that. He assumed that he had been absent for at least two hours, during which the details of his life, since his childhood until the present moment, passed before of his eyes like a movie film. He literally described it as "I was watching a movie about my life".

I did not believe that story in time. I was inclined to believe that it was some kind of those familiar exaggerations.

Five years later, I heard another story that was almost identical to the previous one, but this time it belonged to a young man who had a violent traffic accident while driving his motorcycle. It was exactly the same. The details of his whole life, since early childhood till the present moment, passed before his eyes like a movie film within seconds.

As I progressed in my undergraduate studies, I learned quite a bit about how the human brain works, and I realized that the two stories I heard before were not far from the truth. Moreover, through "forensic medicine", I learned that the person sentenced to death by hanging, and at the moment of the execution, sees identical visions of the details of his previous life. Through the history of medicine, I have also learned that curiosity has enabled many doctors to examine these visions themselves by placing themselves in similar circumstances, and some of them have died in their attempts.
The only common denominator among all these cases is that they coincided with cerebral hypoxia due to the interruption of blood flow to the brain.

To understand this phenomenon, it is necessary to talk about the mechanism of action of the brain, but very briefly, as I do not want to turn this subject into a boring lesson in physiology.

There are dozens of neurotransmitters discovered to this day, but the most famous ones are: Acetylcholine, Adrenaline, Noradrenalin, Dopamine, Serotonin and Melatonin, most of which have been discovered since the beginning of the last century.

In the late 1970s and early 1980s, an amazing new group of neurotransmitters, Endorphins, was discovered. That discovery was truly a revolutionary breakthrough in medicine, changing most of the concepts that prevailed until recently, and enabling us to better understand how our human brain works. Endorphins, the means of happiness, joy, ecstasy and addiction also.

Have you ever wondered, dear reader, about the secret of ecstasy you feel when you listen to your favorite music, your favorite song, or watch your favorite sports team win an important game, or receive some positive news that you were eagerly waiting for? It is the Endorphins that are released in your brain at that moment.

The same thing happens when you feel super pleasure while you eat your favorite meal. In this case, it starts with the taste papillae in your tongue.

The signal through the neurotransmitters reaches the brain, which translates it as tasty to you, and releases those amazing endorphins that make you feel that pleasure. The same goes for smoking.

Endorphins have mainly analgesic properties, and attenuate stress effects. In addition to those properties, Endorphins also improve the mood and induce some degree of ecstasy and happiness. Its properties, in short, are similar to the properties of narcotic drugs such as morphine and other opiates. Rather, endorphins can be considered as endogenous opiates.

When someone has a broken arm or leg, or when he exposes to any form of acute traumatic injury, his brain releases vast amounts of endorphins that are responsible for reducing the severity of the pain and preventing the development of a pain shock. In most cases, severe pain begins only after many hours of the injury, and paradoxically, after the patient has received treatment.

The mechanism of action of most narcotic drugs relies on stimulating the brain to release more endorphins, hence the addictive behavior.

The difference between substances, drugs or activities, which may turn into addictive behavior, is no more than the difference in the amounts of liberated Endorphins. Then it is obvious that reversing addiction to chocolate or coffee is not as difficult as to reverse addiction to drugs, and the reason is the waterfall of Endorphins in the latter case compared to a small stream in the first two cases.

Physical, and even mental, stress is also a key contributor to the release of Endorphins by the brain. So it is no exaggeration to say that one finds happiness in work or exercise. He is right, that's how his addictive behavior shows.

Excessive appetite for food, and hence obesity, occur according to the same mechanism, which led some pharmaceutical companies to produce expensive drugs act against the mechanism of appetite to 
reduce appetite, echoing the imagination of many who are desperately seeking to get rid of the extra pounds in their weight. Of course, these drugs are not without side effects, some of which may be serious. I personally, disagree with their description or use because I refuse, in principle, to play with brain chemistry in order to achieve a result that can be adequately achieved without those side effects; such as diet and exercise.

In fact, most of the techniques known as alternative medicine, including acupuncture, negative and positive energy concepts, adjust the amount and path of Endorphins themselves. The trip to the other bank; Endorphins are the boat.

When the flow of blood, and thus oxygen, to the brain interrupts, and of course before the brain cells begin to die, the brain translates the situation as a stress, and liberates waterfalls of neurotransmitters, particularly Endorphins and Serotonin, the latter also carries inhibitory properties. In this case, the Endorphins are not just liberated from the same centers as in resting conditions, the pituitary gland as example, but from all other brain centers, from the cortex as well as the core.

Memories which are stored in the multiple cortical regions, and extending from early childhood to the present moment, emanate. Pain sensation, or most of it, fades away at the same time. A state of tranquility, peace, and perhaps joy prevails. The influx of Endorphins accelerates with increased stress induced hypoxia to reach a peak, and as a result, the endorphins associated phenomena accelerate, and then begins to slow down gradually with the onset of brain cells degeneration, until they stop with the complete cell death.

It is very important to point out that those visions that appear at this stage are not visual hallucinations or delusions such as those seen in the case of schizophrenia; the brain does not create them, but only elicits them. They are naturally radically different from dreams as well, both in terms of their nature and in terms of the mechanism of occurrence.

I spent the last week, preparing for this article, reading hundreds of documented testimonies belonging to people who have experienced death around the world, meaning they have died clinically for a period of time ranging from 20 seconds to nine minutes.

All those testimonies focused on the details they had experienced and the visions they had seen during that period of absence.

The common denominator of all these experiences and visions is that they are derived from stored memory, distal or proximal, and there was never a place for hallucination.

Some saw beloved ones who had already lost them, and those dear ones either expressed their longing for the reunion or urged them to return to life because their time is not yet ripe.

Some, on the contrary, saw beloved ones who were in the personal or family environment, and those beloved ones either said goodbye to them or incited them not to be absent.

Some have seen experiences they have already witnessed; positive or negative experiences.

Some testimonies were totally neutral. All they experienced was that they saw themselves watching the efforts of the doctors or the paramedics to rescue them, in a completely neutral emotional state.

And many other details that falls within the same classification and do not go beyond it. But details with sensual aspects were never mentioned, not even in a single testimony. I have not read among all those testimonies any single detail, even transiently, related to desires, whatever the direction that these desires could take.

When asked about the conclusion they reached, the lesson they learned, or the philosophy they created, based on their experience with death, regarding the existence or non-existence of another life after death, their responses varied according to their cultural and religious (or non-religious) backgrounds.

Some of them denied the existence of another life, and considered that the person who dies... dies... but he remains alive in the memory of his beloved ones or in the memory of the generations if he has achieved in his life what makes him immortal. In other words, the other life, in the view of those, is a "thought" rather than a "being."

Others were nihilistic, melancholic, and considered that death is equivalent to total absence or vanishing.

The larger proportion, as expected, considered that other life is a fact and a reality, and that those who leave the earthly life move to live in peace and tranquility with their predecessors $[5,6]$.

But again, nobody ever mentioned sensual details in any aspect of the other life as they see it.

\section{Twenty-one grams}

In 2003, a dramatic movie entitled "21 Grams" by Sean Penn, Naomi Watts and Benicio Del Toro was released. It includes three narrative tracks about six people who have experienced or closely examined the window between life and death. The title of the movie is literally inspired by the myth; the weight of the human body is reduced at the moment of death by twenty-one grams, which is equivalent to the "mass of the soul" that has just left the body of the deceased [7].

I am not going to write a critique of that movie, which I enjoyed it very much by the way, and it was one of the movies that had a profound impact on me, but I searched for the origin of this myth, especially since this idea itself about the mass of the soul has been repeated in many movies and series, before or after the release of that film, as in many songs' lyrics, and even in some novels. The origin of this myth is an alleged search by a US doctor from Massachusetts called "Duncan McDougall" in the early 20th century. The New York Times published a news story about his research in 1907, and then the research was published in the Journal of the "American association of Psychological researches" in April of the same year.

\section{Methodology}

The study involved six people who are at risk of dying from end stage TB and are staying in a sanatorium for the elderly. McDougall used an industrial sized scale that was sensitive within five and a half grams margin of error, placing each of those patients with the entire bed on the scale to record weight differences during the last hours of life and at the moment of death. The second stage of the study was conducted on 15 dogs, and their weights were recorded immediately before their death and the moment of death, exactly in the same way as before.

The result of the study, as McDougall announced it, was that the weight of the human had dropped by twenty-one grams at the moment of death, and concluded that this difference in weight was the weight of the mass of the soul that had departed the body. 
McDougall also discovered that the weights of the dogs had not changed at all, and concluded that dogs have no souls [8].

When McDougall was discussed in the details of his alleged research, his research turned out to be nothing but nonsense. McDougall initially ruled out the reading of two patients (or bodies or cases, as you wish) covered by the research for technical difficulties. That is to say, the research included four cases, not six as alleged. The 21 grams result he found it in only one case, which is the first case he investigated. In a second case the weight dropped a number of grams at the moment of death, before returning to what it was originally exactly few moments later. In the other two cases, weight dropped a number of grams at the moment of death, and additional grams were dropped after a few minutes.

The scientific explanation of what happened is more than simple. At the moment of death, an increase of the temperature happens because the lungs stop playing their role in "cooling blood", before it reduces later when the blood is coagulated inside the vessels. As a result of the increased temperature, a loss of fluids occurs through sweating, so it is common to lose weight slightly, and this varies depending on the effectiveness and distribution of the sweat glands. And the fact that the weight of the dogs did not decrease at all, is not because they have no souls, but because bodies of the dogs devoid of sweat glands.

\section{It is that simple.}

The result of this alleged research was refuted from the very first moment of its publication, but the legend, it has launched, has continued to be alive to this day.

I do not want anybody to understand that I am trying here to discuss the idea of the existence or non- existence of the soul, not at all. All what I am trying to say is that the soul, if exists, is not an entity that has a mass. less.

For me, the soul is best described as a "concept", no more and no

\section{Conclusion}

In an interview with an American friend, he is a "Darwinian" by the way, and I already told him that I am preparing for this article, I asked him: What about you? Do you think there is other life after death? "I do not know exactly," he replied, and resumed: "Actually, I look at death as a long sleepless dream. But I believe that terrestrial life occurs over time cycles, each of which may span one million or perhaps a billion years. You die, but you leave behind molecules of DNA, and these are not vanished. A day may come a million or a billion years after your death, and you may come back to life again, through your DNA."

\section{In fact, I find it a worthwhile idea.}

Finally, I would like to draw attention to the fact that, although I have been careful in presenting the scientific and medical details in this article, I, on the other hand, have sought to simplify and avoid diving into particles that do not concern the non-specialist reader, and I deliberately neglected reference to many complex physiological aspects.

It is therefore noted that this article should not be treated as a medical article. It is best, perhaps, to treat it as an intellectual article only.

\section{Acknowledgement}

I would like to express my sincere thanks and gratitude to the great man who, through his unconditional love, caring and support, has made me the person I am today.

To my father I dedicate this article.

\section{References}

1. Griffith LJ (2009) Near-death experiences and psychotherapy. Psychiatry (Edgemont) 6: 35-42.

2. Lommel PV (2010) Consciousness Beyond Life: The science of the neardeath experience. HarperOne.

3. Sleutjes A, Moreira-Almeida A, Greyson B (2014) Almost 40 years investigating near-death experiences: an overview of mainstream scientific journals. J Nerv Ment Dis 202: 833-836.

4. Poeaknapo C, Schmidt J, Brandsch M, Dräger B, Zenk MH (2004) Endogenous formation of morphine in human cells. PNAS 101: 14091-14096.

5. Gina K (2008). Yes, Running Can Make You High. The New York Times.

6. Is there a link between exercise and happiness?

7. Karl K (2006) Great Mythconceptions: The Science Behind the Myths. Andrews McMeel. 199-201.

8. Duncan MD (1907) The Soul: Hypothesis Concerning Soul Substance Together with Experimental Evidence of the Existence of Such Substance. Am Med 2: 240-243. 